\title{
AUTOHESION OF INORGANIC COMPOUND POWDERS
}

\author{
A.V. Smirnov', V. P. Tarasovskii', V. V. Belov'2, V. V. Rybal'chenko', A. A. Vasin', \\ O. L. Sidortsova ${ }^{1}$ and A. D. Shlyapin ${ }^{1}$
}

${ }^{1}$ Moscow Polytechnic University, Bolshaya Semenovskaya str., 38 Moscow, 107023, Russia

${ }^{2}$ Tver State Technical University, Afanasy Nikitin embankment, 22 Tver, 170026, Russia

Received: May 22, 2018

\begin{abstract}
The article begins with analytical review of the works performed from 1940 up to nowadays, concerning the phenomenon of autohesion in the powders of inorganic compounds. The issues of terminology are concerned, the difference is discussed between the phenomena of autohesion, adhesion, and cohesion. Three groups of the components of autohesion forces are considered: van der Waals and electrical forces, cohesion and capillary forces and mechanical cohesion, as well as internal and external factors affecting these forces.

The second part of the article is devoted to the results of experiments performed to study the influence of the autohesion forces on the properties of friable inorganic powder materials. In particular, the rheological properties of powders were studied by static and dynamic methods on four kinds of electrocorundum powder with similar particle size and particle size distribution corresponding to the class of grinding powders F1200 according to FEPA standard. Special attention is paid to assessing the effect of humidity on technological properties of the powder, obtained by spray drying of ceramic slurry. This powder is widely used as a component of building mixes.

The authors came to conclusion that detailed study is necessary of the autohesion effect on the parameters of friable systems for the rational choice of technological modes. The work can be useful for researchers and practitioners associated with the problems of processing, storage and transportation of powder materials.
\end{abstract}

\section{INTRODUCTION}

Powders or powder materials are a kind of friable materials. These are materials, consisting of many individual particles. Friable materials are also called granular or dispersed. The utmost sizes of powders are not exactly defined; the most common size ranges from $0.1 \mu \mathrm{m}$ to $500 \mu \mathrm{m}$. In some industries, powder size limits may significantly differ from the average range. For example, in manufacturing refractories they call powders friable materials with particle size less than $4 \mathrm{~mm}$ [1].

The autohesion of powder particles is a power interaction between the contacting particles, which prevents them from separation. Autohesion is de- termined by the tensile strength of contacts between powder particles [1,2]. Autohesion is caused by the forces of different nature. The phenomenon of autohesion covers all possible types and forms of power interaction of the powder particles, regardless of the number of particles, their properties as well as causes and conditions of occurrence of this phenomenon.

The difference between autohesion and similar phenomena, such as adhesion and cohesion, is ambiguously defined by various authors. There are two common definitions of the differences between autohesion and adhesion:

The first definition is - autohesion is the power interaction of particles with each other (with no dif-

Corresponding author: V. P. Tarasovskii, e-mail: tarasvp@mail.ru 
ference between similar particles and a mixture of dissimilar powders), while the adhesion is the interaction of particles with the solid surface of macroscopic bodies [1,3,4,7,10-12];

The second definition is - the autohesion, unlike adhesion, is a power interaction (or bonding) of the particles with similar composition and structure, while adhesion - is the bonding together of dissimilar particles, or that of particles with a solid surface of macroscopic bodies [5,6,8,9]. The first definition is accepted for further consideration.

There are also two definitions in the scientific literature denoting the cohesion phenomenon. First - cohesion is the chemical bond between atoms, ions, or molecules within a body that determines that body's ability to withstand external action. When solid particles interact, cohesion can occur in the area of their direct contact $[1,12]$. However, in a number of publications, there is another definition of powders cohesion. The second definition of cohesion is the power interaction of particles, ensuring their adhesion into agglomerates. At the same time, the power interaction is explained by the forces of various nature, rather than only by those of chemical bonds between molecules, atoms and ions [1316]. This definition of cohesion coincides with that of autohesion [1,2] and can be considered synonymous. Therefore, in the article's text we will mean the first definition of cohesion.

Autohesion largely determines the technological properties of powders and other friable materials. The autohesion forces effect on the strength and rheological characteristics of friable materials and their compacts. The value of autohesion, in turn, is determined by a number of factors, such as: chemical composition and structure of the particle material, morphology, size distribution, humidity, the presence of surfactants, the method and conditions of forming blanks. Moreover, the particles' interaction becomes the stronger, the smaller is their size and becomes decisive in the nanoscale range. The particles autohesion prevents them from mutual movement and separation, thus increasing the ability of the powder to withstand shear and tensile forces. This fact is important in powder processing, since deformation, compaction, caking, flow and loosening powders is associated with the destruction of original structure and, consequently, with overcoming its strength [1].

From the view point of technology processes autohesion can exert either positive or negative effects. Autohesion has a beneficial effect when it is necessary to reduce powders dispersion or prevent delamination of the powder mixture. On the other hand, in the process of powders mixing homogeneity can be significantly disturbed resulting from the formation of aggregates $[1,13,14,16]$. In addition, the negative impact of autohesion manifested in the formation of powder billets, transportation and storage of powders. This is because the forces of autohesion promote caking and formation of vaulted structures, formation of arches on outflowing powders from bunkers and other containers [1,11,13,14,17-20].

Research of autohesion of powder materials, including those inorganic, is an urgent task for modern applied science, engineering and technology. This is explained by that the processing, storage and transportation of powders are widely used in various industries in the production of ceramics, refractories, concrete, composite materials for various purposes, biomaterials, electronics, food and cosmetics [1,13,21]. Main purpose of autohesion research is to predict the properties of powder materials and a rational technology of their processing, storage and transportation [1].

\section{FORCES OF AUTOHESION}

The autohesion of a great number of powder particles consists of the forces of interaction of individual particles at the points of their contact. Besides, the autohesion is determined by the arrangement, shape and size of the particles. Thereby, the presence of a great number of contacting powder particles influences the magnitude of the forces of autohesion of individual contacts [1].

The force required for separation of contacting particles is called the autohesion force. It differs considerably for various friable powder materials under different conditions. Therefore, the notion is used of autohesion ability which is a comparative characteristic denoting the intensity of the autohesion force for a particular granular material under certain conditions [1]. Autohesion ability relates to the main groups of properties of powder materials (Fig. 1).

The autohesion force is the sum of forces of different nature, including the forces of molecular interaction (van der Waals forces and cohesion), electric forces (divided into Coulomb (electrostatic) and those caused by the potential difference of contacting particles), capillary forces and forces of mechanical cohesion. Autohesion of a certain friable powder material may be caused by the action of several forces simultaneously. Electric and capillary forces are the only which are mutually exclusive [1,2].

In general, the components of autohesion force are divided into three groups [1]: 


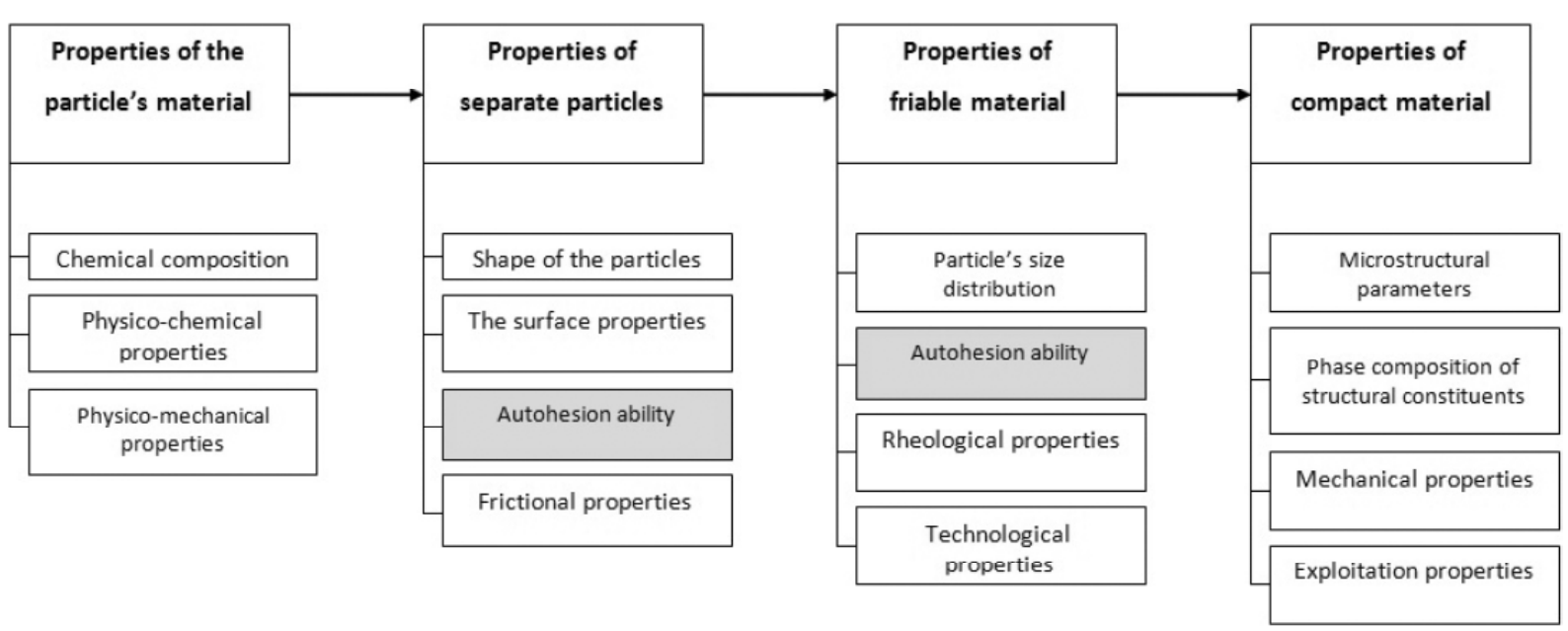

Fig. 1. Classification of the properties of powder materials (replotted regarding to the data from [2]).

The first group - van der Waals and electric forces are manifested spontaneously in the interaction of both individual particles and their clusters;

The second group - cohesive and capillary forces manifest under appropriate conditions: external mechanical force (for pressing the particles to each other) or presence of moisture in the friable powder material;

The third group - the forces of mechanical cohesion, manifesting themselves only on autohesion interaction of a great number of particles.

Analysis of the relationship between the particles' size and the order of autohesion force magnitude for different types of powder materials reveals the contradictory character of existing experimental data. The experimental results of various papers concerning the relationship between the average size of powder particles and their apparent density [22 show a general trend of decreasing the density with decreasing average particle size.

The critical particle size, below which the autohesion forces begin to play a dominant role in the structure formation of powder backfill differs for different authors by two orders of magnitude: from 150 microns for particles of loose building mixtures [23] to 0.2 microns for particles of oxide-nitride ceramic powder [24]. On average, the critical particle size at which the bulk density decreases sharply ranges of 50-60 $\mu \mathrm{m}$ [25]. In classic works on autohesion, the average critical particle size is from $100 \mu \mathrm{m}[1,15,16]$.

Such significant difference can be caused by the complex mechanism of action of the forces of different nature. The complexity is additionally increased due to the fact that the interaction forces of particles depend on the properties of the particle' mate- rial, their morphology, quantity and fractional composition $[26,27]$.

In [17] the effect was studied of fractional composition of spherical glass particles (ranging from 5 to 42 microns in $\mathrm{dm}$ ) on the apparent density. The studies were carried out both experimentally and by computer simulation using the discrete elements method [28]. It was concluded that for increasing the accuracy of predicting apparent density the van der Waals forces have to be taken into account, and in further studies it is necessary to analyze the effect of humidity and method of compaction. The influence of surface characteristics and material properties of the particles was not taken into account.

The authors of [28-32] experimentally studied the forces of molecular interaction of spherical particles of metal and ceramic powders using the atomic force microscopy. The main conclusion of these works consists in that the calculated and experimental data may differ by decimal order. The forces of molecular interaction between particles are determined not only by their chemical composition but also by the composition of absorption layer on their surface and its roughness. Therefore, the calculated values of molecular interaction forces are estimating.

In [33] the effect was studied in detail of electrostatic charging the surface of powder particles in the process of their mixing and grinding. A review was given of methods for determining the presence, sign and magnitude of electrostatic charge. It was concluded that the electrostatic interaction of particles can play a decisive role in the formation of structure of friable powders and lead to the formation of particle aggregates. The authors of [34], who modeled the application of the powder layer on the 


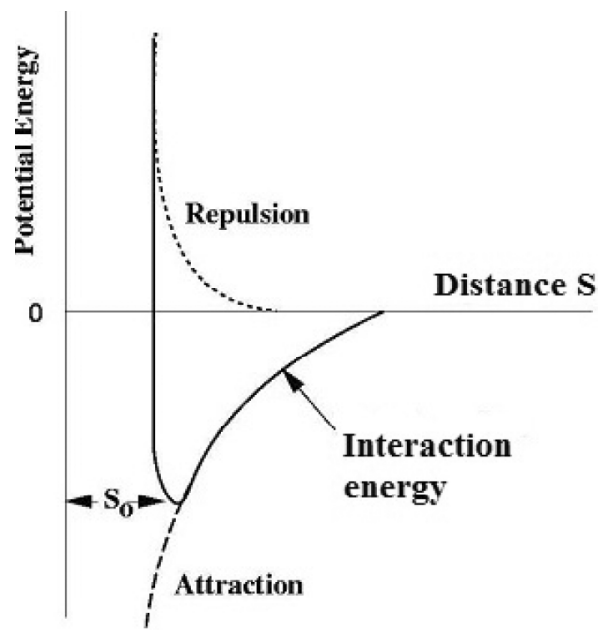

Fig. 2. Potential energy of van der Waals interaction between two particles: So - the distance of stable equilibrium between the repulsion and attraction forces (replotted regarding to the data from [13]).

working surface for selective laser fusion, emphasized the importance of taking into account the electric forces.

Analysis of publications concerning the forces of autohesion in friable powder materials showed, on the one hand, the importance and urgency of this matter, and on the other hand, the lack of systematic and statistically reliable data concerns the influence of autohesion forces on the structure and rheology of friable materials. This is especially true in the case of specific types of materials-ceramic, metal, polymer, dry building mixtures, composite, as well as for the dependence of the autohesion forces on the morphology of powder particles and their surface characteristics.

\subsection{Molecular interaction forces}

The forces of molecular interaction are divided into van der Waals and cohesion forces. These two components of autohesion force differ in the intensity and long-range interaction. The van der Waals component of the autohesion force has an average range value of $10^{-7} \ldots 10^{-8} \mathrm{~N}$. The average value of cohesion force is much larger and is about $10^{-4} \ldots 10^{-7} \mathrm{~N}$ [1]. Van der Waals forces act at a certain distance, while the cohesion forces manifest only on direct, so-called atomic contact of particles [1].

Van der Waals forces manifest themselves mainly in the dry non-compacted friable powders. The magnitude of these forces depends on chemical composition, structure of interacting particles and the distance between them [1]. From the physical point of view, van der Waals forces are caused by induced electrostatic attraction between molecules. Attraction occurs when electrons are grouped on one side of a molecule thus creating a temporary small negative charge on one side and a positive charge on the other. This is how the polar molecule is formed. The adjacent nonpolar molecule will also tend to become a polar molecule with opposite polarity on the side close to the polar one $[13,35]$. Thus the forces of molecular attraction arise, called van der Waals forces. When the distance between the powder particles becomes very small, of the order of Angström, electron clouds associated with atoms and / or molecules of individual particles overlap and repulsive forces occur (Fig. 2) [13].

Cohesion forces cause the interaction (adhesion) of molecules, atoms or ions within a single phase (homogeneous part of the system). The cohesive forces have the same nature as the forces acting between the elements of the structure inside the powder particles, i.e. the forces of chemical bond. For the appearance of cohesion it is not enough to create the direct contact of particles. In most cases, there are adsorption and oxide films on the particles' surfaces preventing the manifestation of cohesion. Therefore, it is necessary to apply an external force to the loose powder material to deform the particles and create the juvenile surfaces'. A cohesive power interaction occurs between juvenile surfaces of contacting particles [1]. Thus the so-called cohesive contact is formed when the forces of chemical bond appear between atoms, ions or molecules of two contacting particles on their juvenile surfaces. The regularities of the formation of cohesive contacts between solid crystalline particles were studied experimentally in [36]. Up to a certain threshold clamping force of the two crystals to each other, the strength of the contacts corresponds to that of van der Waals forces, i.e. does not exceed $10^{-8} \mathrm{~N}$. On further increasing the clamping force, the contact strength of the crystals increases. The autohesion force reaches $10^{-7} . .10^{-6} \mathrm{~N}$. This increase in the strength of the contacts manifests the appearance of the cohesive component of autohesion.

\subsection{Forces of electrical interaction}

The forces of electrical interaction significantly contribute to the autohesion of friable powder materials. The magnitude of electric component of autohesion force may vary in the range of 10 to 1,000 $\mathrm{kPa}$. In some cases, the forces of electrical interaction may exceed those of molecular interaction [1]. The forces of electrical interaction are divided 


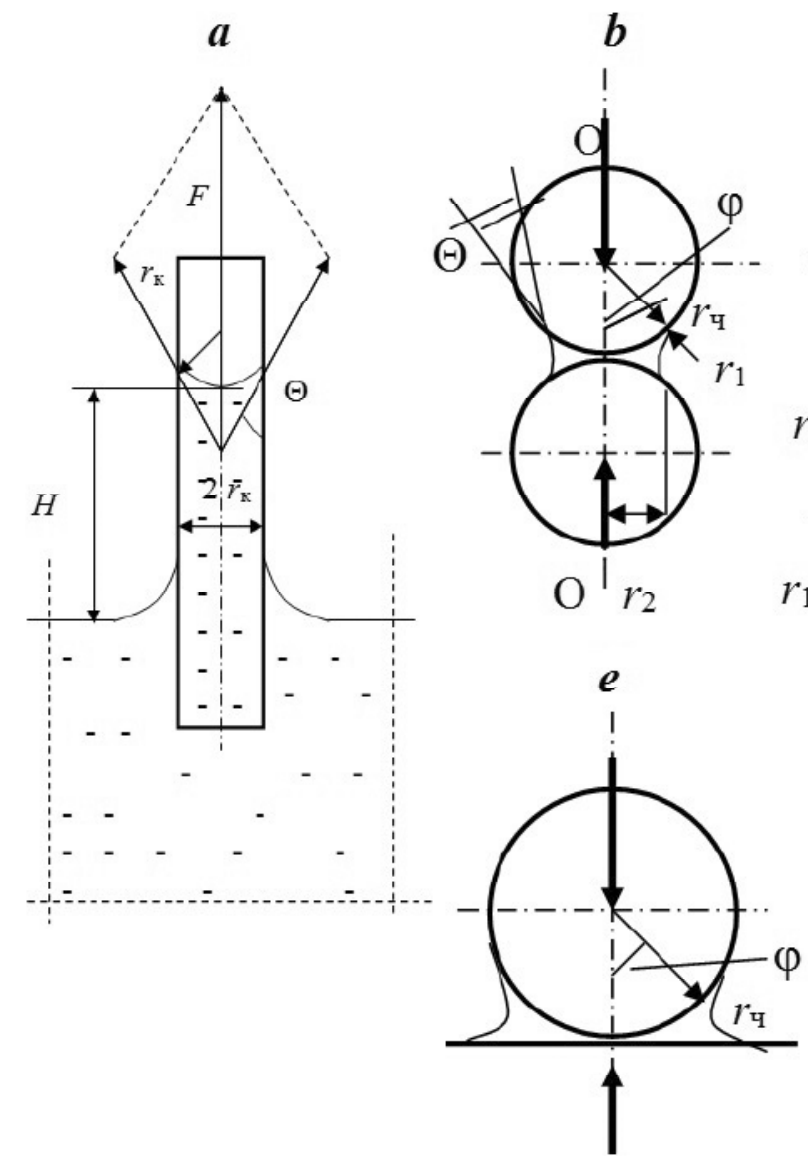

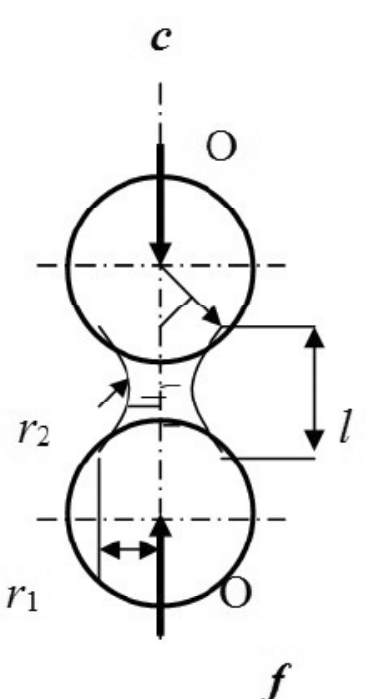

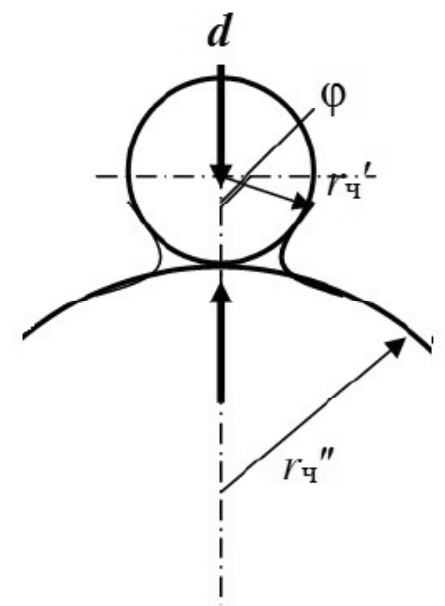

$g$
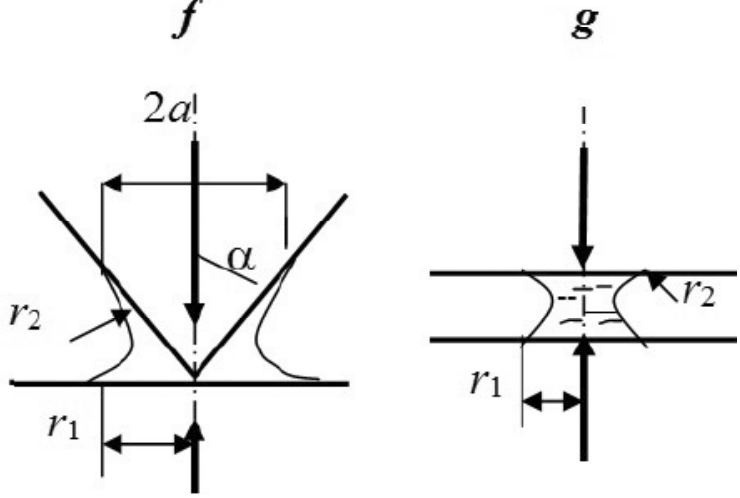

Fig. 3. Capillary raising liquid in the tube and forces of capillary cohesion between two particles.

into actual electrical and Coulomb (electrostatic) forces.

Electric forces arise on contact between the particles, when donor-acceptor processes occur resulting in a double electrical layer. The formation of a double layer in the contact zone is caused by electrical heterogeneity of the surface of contacting particles $[1,12]$.

The electrostatic component of the autohesion force may be the result of friction which electrostatically charges the powder particles due to the transfer of electrons between the particles [37]. The most common electrostatic force is the Coulomb force, presenting the case when both contacting particles are charged [38]. With positive Coulomb force the particles repel each other, if the force is negativethere will be an attraction between the interacting particles. It is also worth noting that, like the van der Waals forces, electrostatic forces act at some distance. This distinguishes them from other components of the autohesion force of [37].

\subsection{Capillary forces}

During long exposure of friable powder in moist air or after introducing into powder a sufficient amount of liquid, the formation of adsorption layers of maximum thickness is accompanied by liquid accumulation in the gaps between the particles which are retained there by the surface tension forces. The liquid "cuffs", are formed limited by the meniscus of twofold curvature. The appearance of meniscus in the contact areas generates in addition to the listed above kinds of autohesion forces, one more system of forces caused by the surface tension of liquid and capillary pressure.

Resulting from the interaction of liquid molecules and the material of capillary wall (wetting by liquid capillary wall), as well as due to the action of surface tension forces of the liquid $\sigma$ its surface is bent, forming a concave meniscus. This leads to the appearance of capillary pressure $P_{K}$ and raising the liquid to the height $H$ (Fig. 3a). The $P_{K}$ value is directly proportional to the surface tension of liquid ó and inversely proportional to the capillary radius $r_{k}$. Further, from the law of Laplace it follows that:

$$
P_{\mathrm{K}}=\frac{2 \sigma \cdot \cos \theta}{r_{\mathrm{K}}}
$$

where $\theta$-interfacial angle. 
In [39] it is shown that the total force pressing two identical spherical particles to each other caused by negative (Laplace) pressure in the liquid located in the gap between them (Fig. 3b), as well as by the tightening action of surface tension is determined by the following expression:

$$
F=\sigma\left[\pi r_{P}^{2} \sin ^{2} \phi\left(\frac{1}{r_{2}}-\frac{1}{r_{1}}\right)\right]+
$$

$2 \pi r_{p} \sin \phi \cdot \sin (\phi+\theta)$,

where $r_{\mathrm{p}}$ is the particles radius, $\varphi$ is the angle depending on the amount of liquid in the gap between the particles, $r_{1}$ and $r_{2}$ are the radii of meniscus curvature.

In fact, the meniscus surface is not circular, since its curvature is changed by gravity [40], as well as by the wedging pressure of polymolecular adsorption liquid layer being in equilibrium with the meniscus [41]. However, the error allowed in the approximation of the meniscus profile by the arc of the circle is relatively small for particles with a diameter less than $1 \mathrm{~mm}$ [39] and, therefore, the total force tightening these particles can be determined by the formula (2) .

In friable powder materials the contacts are also possible of particles with different radius (Fig. 3d), in the limit-the ball and the plane (Fig. 3e), as well as the contacts of the cone top and plane (Fig. 3f) and two planes (Fig. 3h) $[42,43]$.

For the sphere - plane contact of the (Fig. 3e) the force $F$ is equal to [44]:

$$
\begin{aligned}
& F=\sigma\left[\pi \cdot r_{4}^{2} \cdot \sin ^{2} \varphi \cdot\left(\frac{1}{r_{2}}-\frac{1}{r_{1}}\right)+\right. \\
& \left.2 \cdot \pi \cdot r_{4} \cdot \sin \varphi \cdot \sin (\varphi+\Theta)\right] .
\end{aligned}
$$

For the "cone top-plane" type contact (see Fig. 3f) with a layer of liquid with the thickness of / between them, the force $F$ is equal to [42]:

$$
F=\sigma \cdot\left[\pi \cdot a^{2} \cdot\left(\frac{1}{r_{2}}-\frac{1}{r_{1}}\right)+2 \cdot \pi \cdot a \cdot \cos (\alpha-\Theta)\right] \text {. }
$$

On contacting the particles with flat surfaces (Fig. $3 \mathrm{~g}$ ), if the distance between them remains constant, the force $F$ increases with $r_{1}$, i.e. with increasing the volume of liquid in the contact zone [44].

If instead of two particles, they consider separate aggregates of particles (Figs. $4 a$ and $4 b$ ) and the three-phase disperse system as a whole, which fragment is shown in Fig. 4b, then in each contact between the particles the menisci are formed, and the forces of capillary adhesion appear, which are called internal ones [45]. The capillary adhesion in such aggregates and systems is determined by the total value of internal forces of capillary adhesion acting between the particles. When all the internal pores of the aggregate are filled with liquid, this is a two-phase system, and the menisci form only on the outer surface of the aggregate (Fig. 4d). The negative pressure created by these menisci results in the all-round compression of the aggregate by external capillary forces. With a large liquid content the menisci on the aggregate surface disappear, and the particles are held together by the surface tension together with other types of autohesion interactions.

Capillary adhesion is manifested if the friable powder material is held for some time in the air with a relative humidity of more than $60 \%$. Thereby, the prevalence of capillary adhesion over the other components of autohesion is appreciable for the particles with a diameter of over $10 \mu \mathrm{m}$ [12].

The authors of $[46,47]$ noted that capillary adhesion manifests itself already at hygroscopic humidity, thereby the bond between the particles being significantly weakened by the particles' surface irregularities [47].

\subsection{Mechanical forces}

In addition to molecular, electrical and capillary forces, the properties of the friable powder material are also influenced by mechanical forces. These include forces caused by mechanical engagement of particles (Fig. 5a) and also by mechanical interaction of adjacent particles. This interaction leads to the appearance of the so-called bearing force (Fig. 5b) [1].

Mechanical engagement occurs when the shape of the particles deviates from the spherical shape. Increasing the particles' shape complicacy is accompanied by increasing probability of their mechanical engagement. The mechanical forces counteract external pressure and due to the weight of the powder particles include the supporting mechanical force. The role of the bearing force and reasons for its appearance are shown in Fig. 5b. To separate the particle II from the common layer, it is necessary to apply an additional force equal to the weight of the neighboring particles I and III resting on it [1].

$\ln [1]$ it is assumed that the value of the bearing force increases proportionally to the cube of the particle diameter. When determining the breaking 

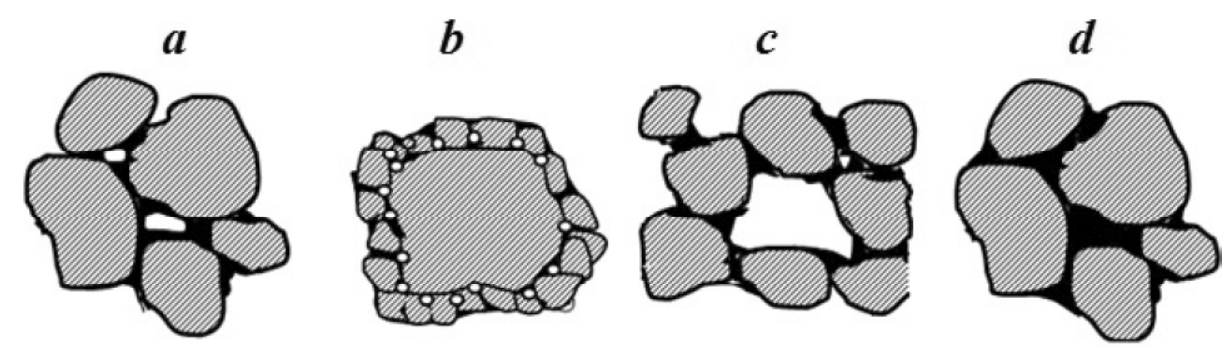

Fig. 4. Capillary structures in disperse systems: a -three-phase grain, b/ - three-phase globule, $C$ - cellular-globular structure, d- two-phase grain (replotted regarding to the data from [45]).

strength or shear resistance of friable powders the force is consumed not only to overcome the of autohesion force, but also to move and displace the neighboring blocking particles. For particles of small size (less than 20 microns), this force is negligible. With the growth of particle size, the bear force increases and affects the strength characteristics of friable powder materials.

\section{EXPERIMENTAL STUDY OF THE INFLUENCE OF AUTOHESION FORCES ON THE PROPERTIES OF FRIABLE INORGANIC POWDER MATERIALS}

\subsection{Comparative analysis of rheological properties of corundum powders}

To assess the influence of the autohesion forces on the rheological properties of the alumina powders the study was carried out of powders rheology by static and dynamic methods. Four grades of electro corundum powder were selected for research having similar particle size and granulometric composition, corresponding to the grinding powders class F1200 according to FEPA standard,. Powders manufactured by different manufacturers are designated as: "type 1", "type 2", "type 3", "type 4".

The powders particle size distribution was analyzed by backscattering laser radiation in aqueous medium using the Fritsch Analysette 22 laser

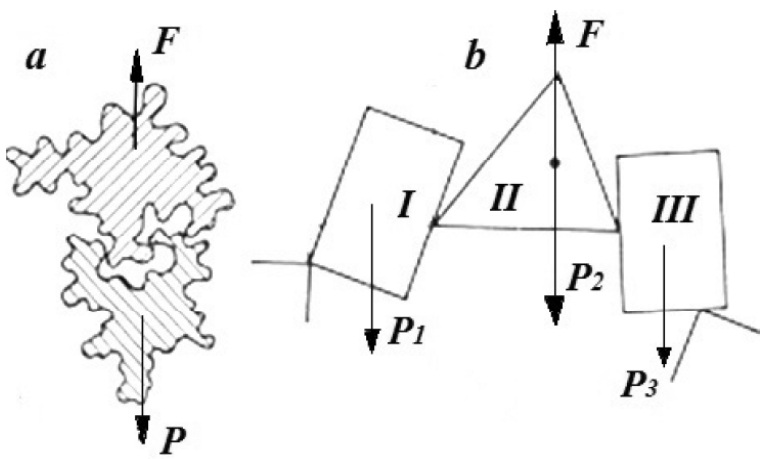

Fig. 5. The scheme of the action of mechanical forces: $a$ - forces of mechanical engagement; $b$-the bear mechanical force (replotted regarding to the data from [1]).

particle analyzer. The results of the analysis are presented in Table 1.

Determination of specific surface area and average powders particle size were determined by estimating the gas permeability using the Kozeny-Carman equation [48]. The method of measurement consists in determination of the passage time of a fixed air volume through the sample layer [49]. The measurement results are presented in Table 2.

As can be seen from the measurement results (Tables 1 and 2) all four types of corundum powders practically do not differ in particle size distribution and average particle size. A significant difference is observed only in the specific surface area of the powder particles (Table 2). The variation range is $4665 \ldots 7338 \mathrm{~cm}^{2} / \mathrm{g}$, while that of average sizes is within 0.8 to 3.8 microns (measurements on the laser analyzer) and within 2.0 to 3.2 microns (meas-

Table 1. Results of particle size analysis of corundum powders.

\begin{tabular}{lcccc}
\hline \multirow{2}{*}{ Name of parameter } & \multicolumn{4}{c}{ Type of powder } \\
& Type 1 & Type 2 & Type 3 & Type 4 \\
\hline Size of particles, $D_{50}, \mu \mathrm{m}$ & 1.8 & 1.3 & 0.5 & 1.6 \\
Size of particles, $D_{90}, \mu \mathrm{m}$ & 5.0 & 3.2 & 2.0 & 4.2 \\
Average size of particles, $\mu \mathrm{m}$ & 3.8 & 1.7 & 0.8 & 3.0 \\
\hline
\end{tabular}


Table 2. Particle size analysis of corundum powders.

\begin{tabular}{lll}
\hline $\begin{array}{l}\text { Type of } \\
\text { powder }\end{array}$ & $\begin{array}{l}\text { Specific powder } \\
\text { surface, sm²/g }\end{array}$ & $\begin{array}{l}\text { Average size of } \\
\text { powder's } \\
\text { particles, } \mu \mathrm{m}\end{array}$ \\
\hline Type 1 & 6274 & 2.4 \\
Type 2 & 5714 & 2.6 \\
Type 3 & 7338 & 2.0 \\
Type 4 & 4665 & 3.2 \\
\hline
\end{tabular}

urements by gas permeability assessment). This may indicate a difference in the surface structure of the powder particles, i.e. the difference in the average number of the surface irregularities and defects.

Apparent density and density after shaking, related to rheological properties of friable materials, were determined by the static method according to procedure described in $[50,51]$. The apparent density was determined by measuring the mass of alumina with known volume collected after free uniform filling a stationary container with powder through a funnel in the absence of vibration followed by vibrating the container with powder. Thereby, the diameter of the funnel outlet was $5 \mathrm{~mm}$, and the amount of powder used for one measurement was $10 \mathrm{~cm}^{3}$. The modes of vibration were as follows: amplitude $-0.5 \mathrm{~mm}$; frequency - $50 \mathrm{~Hz}$; the vibration time $-60 \mathrm{~s}$. The moisture content of the powders in all experiments did not exceed $0.01 \%$. The results of these studies are presented in Table 3.
The corundum powder "Type 4" has the maximum energy of $30.4 \mathrm{MJ}$ before the avalanche. This parameter characterizes the magnitude of the force (energy) required to overcome the internal of autohesion forces and add mobility to the powder. The maximum energy value before avalanche for powders "type 1", "type 2", "type 3" is significantly lower and ranges from 7.4 to $11.5 \mathrm{MJ}$. "Type 4" powder is also characterized by the highest values of maximum angle before the avalanche, equal to 74.3 degrees, and the highest value of dynamic density, equal to $1.19 \mathrm{~g} / \mathrm{cm}^{3}$. Using the data of the dynamic analysis of rheology for the presented corundum powders, one can assume that the parameter "maximum energy before avalanche" is correlated with "maximum angle before avalanche" and "dynamic density" parameters. The magnitude of these parameters can be used to estimate the magnitude of the of autohesion forces of friable material.

Comparison of the data on powders' rheological properties, obtained by static and dynamic methods (see Tables 3 and 4) shows that there exists some relationship between the apparent density and the maximum energy of the powder before the avalanche. Both of these parameters can indirectly characterize the autohesion forces operating in the friable material. These forces lead to the formation of agglomerates, thus reducing the apparent density relative to other powders of identical chemical composition and similar granulometry. Power autohesion prevents the avalanches during rotation of the friable material in the drum of the device, which results in higher maximum energy before the ava-

Table 3. Rheological properties of powders determined by static method.

\begin{tabular}{lll}
\hline Type of powder & \multicolumn{2}{c}{$\begin{array}{c}\text { Bulk density of powder, } \mathrm{g} / \mathrm{sm}^{3} \\
\text { After shaking }(\mathrm{amplitude}=0.5 \mu \mathrm{m} ; \\
\text { frequency } 50 \mathrm{~Hz} \text {; duration of vibration } 60 \mathrm{~s})\end{array}$} \\
\hline Type 1 & 0.70 & 1.39 \\
Type 2 & 1.04 & 1.72 \\
Type 3 & 1.00 & 1.36 \\
Type 4 & 1.01 & 1.25 \\
\hline
\end{tabular}

Table 4. Rheological properties determined by dynamic method.

\begin{tabular}{|c|c|c|c|c|}
\hline \multirow[t]{2}{*}{ Name of parameter } & \multicolumn{4}{|c|}{ Powder type } \\
\hline & Tupe 1 & Type 2 & Type 3 & Type 4 \\
\hline Maximum energy before avalanche, deg & 8.0 & 11.5 & 7.4 & 30.4 \\
\hline Maximum angle before avalanche, deg & 61.0 & 69.8 & 62.8 & 74.3 \\
\hline Rest angle after avalanche, deg & 42.2 & 50.6 & 43.2 & 52.1 \\
\hline Dynamic density of powder, $\mathrm{g} / \mathrm{sm}^{3}$ & 1.02 & 1.14 & 1.02 & 1.19 \\
\hline
\end{tabular}


Table 5. The chemical composition of powder obtained by spray drying of ceramic slurry.

\begin{tabular}{lccccccc}
\hline Chemical compound & $\mathrm{SiO}_{2}$ & $\mathrm{Al}_{2} \mathrm{O}_{3}$ & $\mathrm{Fe}_{2} \mathrm{O}_{3}$ & $\mathrm{CaO}$ & $\mathrm{MgO}$ & $\mathrm{R}_{2} \mathrm{O}_{3}$ & else \\
\hline Content, wt.\% & 59.56 & 19.8 & 1.0 & 2.44 & 2.19 & 6.26 & 8.39 \\
\hline
\end{tabular}

lanche, the maximum angle before the avalanche and dynamic density.

The comparative analysis of rheological properties of corundum shows that the autohesion force can considerably differ for the powders with identical chemical composition and similar particle size. It is not enough to analyze the particle size distribution and specific surface area in order to characterize the rheological and technological properties of corundum powders within the size range studied. Therefore it may be necessary to assess the autohesion strength, both fully and its various components, such as molecular forces, electrical, mechanical cohesion forces and capillary forces in order to predict the behavior of such friable powder materials in technological processes..

\subsection{Investigation of the relationship between capillary adhesion and rheological properties of the powder, obtained by spray drying of ceramic slurry}

To assess the effect of moisture on technological properties of the powder, obtained by spray drying of ceramic slurry, used as a component of building mixtures, experimental studies were carried out to identify the relationship between the capillary adhesion and its rheological properties. The chemical composition of the powder sample is shown in Table 5 . The sieve analysis shows that most of the particles have a size $0.25 \ldots 0.5 \mathrm{~mm}(55-60 \%)$. About $15 \%$ of particles have the size of $0.5 \ldots 1 \mathrm{~mm}$ and $25-30 \%$ - that of $0.1 \ldots 0.25 \mathrm{~mm}$. Fig. 6 shows the results of measuring the apparent density of the powder obtained by filling $150 \mathrm{~g}$ of powder into a glass with a capacity of $50 \mathrm{~cm}^{3}$ from a funnel with an orifice diameter of $15 \mathrm{~mm}$, set $10 \mathrm{~cm}$ above the edge of the glass, and then cutting the excess powder to the level of the glass edges. The same figure shows the dependence of the apparent density on the moisture by means of a gutter set at an angle of 60 degrees, since its measurement by the first method at a humidity of more than $16 \%$ was impossible. The apparent density of the powder decreased with increasing humidity up to $18 \%$ and then sharply increased.
The dependencies, shown in Fig. 6, were analyzed together with the data in Fig. 7 for the shear stress limit obtained with the help of penetration rheometer [52] in pressed powder samples at different humidity and relative samples density of: $0.95 ; 1.0 ; 1.05$, and $1.1 \mathrm{~g} / \mathrm{cm}^{3}$ (porosity of samples respectively $62.3 ; 60.3 ; 58.3$, and $56.3 \%$ ). With increasing powder moisture at constant porosity the limit shear stress in the samples and, consequently, the capillary adhesion, increase, reach a maximum at humidity of about $18 \%$ and then sharply decrease.

Thus, the dependence on humidity of the capillary adhesion of the pressed powder and its appar-

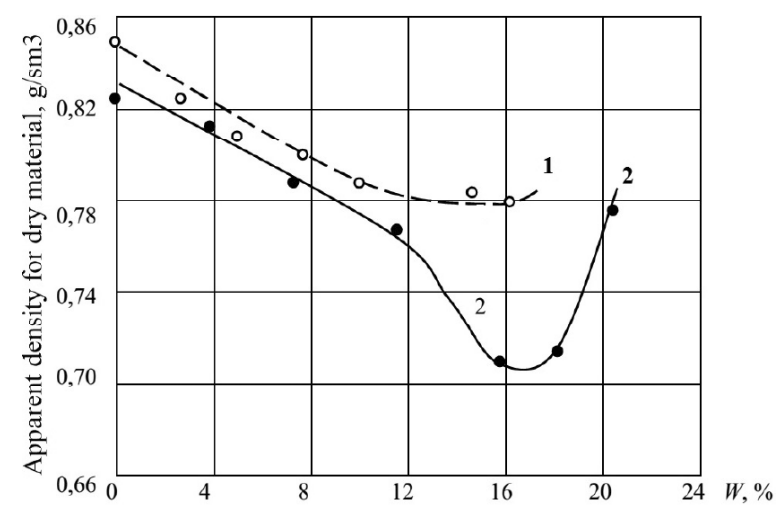

Fig. 6. Dependence of the apparent density of the powder, obtained by spray drying of ceramic slurry, on humidity $W$ when measuring with funnel (1) and gutter (2).

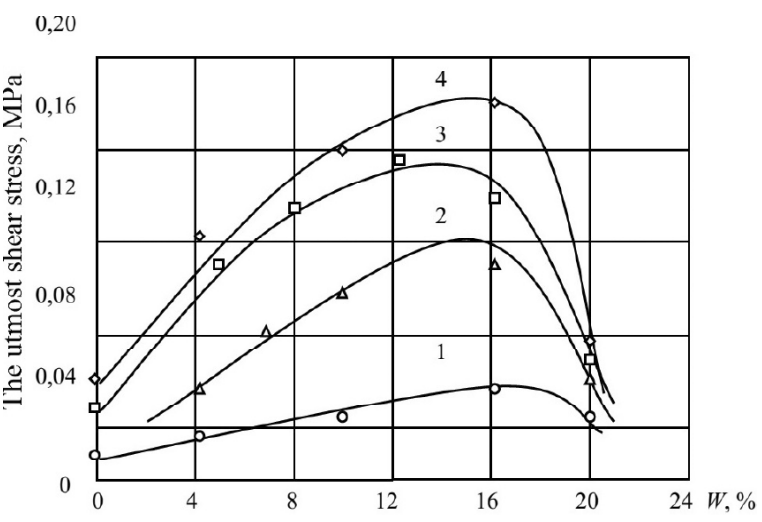

Fig. 7. Dependence of the utmost shear stress in pressed specimens of powder, obtained by spray drying of ceramic slurry, on humidity $\mathrm{W}$ and relative density of specimens 0.95 (1); 1.0 (2); 1.05 (3), and $1.1(4) \mathrm{g} / \mathrm{sm}^{3}$. 
ent density, as well as the presence of extreme values of these properties at a certain "critical" humidity are similar to those observed in dispersions of non-plastic materials with continuous granulometry [53]. However, there are fundamental differences in these dependencies for the powders, obtained by spray drying of ceramic slurry.

The most important difference is that the "critical" humidity for these dispersions corresponds to the saturation of the pores of the friable material with liquid. This fact is explained by the difference in the regularities of adhesion in the dispersions of non-plastic and plastic materials. Unlike from the former elementary particles of the latter are the thinnest plates. It follows from the theory of capillary phenomena that on of particles' contact with flat surfaces (Fig. 3g), with the distance between them remaining constant, the capillary adhesion force $F$ increases with increasing curvature radius of the meniscus $r_{1}$, i.e. together with the increasing the volume of liquid in the contact zone. Therefore, capillary adhesion in these systems increases up to the full saturation of the pores between the particles of the friable material, when the stepwise (in practice, more or less smooth) disappearance of the liquid - gas interface and internal forces of capillary adhesion take place.

Analysis of these data together with those concerning the pressing compaction of powders, obtained by spray drying of ceramic slurry reveals a certain contradiction in previously established relationship between the capillary adhesion and the resistance to compaction by pressing of disperse systems made of non-plastic materials [54]. For powder, obtained by spray drying of ceramic slurry, the improvement of compaction is correlated with the increase of capillary adhesion with humidity increase to its critical values corresponding to the transition of the system into a two-phase state. At the same time, this is not a consequence of the effect of "self-compaction" of dispersions. In particular, on free backfilling with increasing humidity to the specified limit, instead of the decrease, on the contrary, the porosity of the system increases. This means its loosening due to the formation of aggregates from powder granules obtained by spray drying of ceramic slurry under the action of capillary forces. Improving the powder compaction can be explained by a decrease in the internal friction forces in the system. This, in turn, is probably expressed in facilitating the sliding of plate-shaped particles over each other without breaking their bond, which is characteristic of plastic materials.
When compacting the dispersion of plastic material (with the particles being the thinnest plates as is the case in the powder in question) by pressures exceeding 10-20 MPa, the increased humidity contributes to this process by facilitating the sliding particles relative to each other without breaking their bond. Simultaneously the increase takes place of capillary adhesion and of plastic strength of the system. This continues up to the critical humidity values corresponding to the applied pressures, when further compaction of the system becomes impossible due to its approach to the two-phase state. One could expect that in this state, capillary adhesion should sharply decrease due to the menisci coalescence. However, in practice, this does not happen, since the pressure removal is followed by compulsory compression porosity caused by elastic expansion. The compression porosity, in turn, automatically preserves the action of in the full volume capillary adhesion. Thus, at critical values of the powder humidity the maximum of capillary adhesion is spontaneously set corresponding to the given system density. These specified humidity values are optimal from the viewpoint of the maximum cohesion in the system, its greatest compaction degree, as well as from the viewpoint of the greatest strength of annealed products [55]. Therefore, in practical use of the results obtained it is necessary to apply the discussed above understanding the role of optimal powder moisture as a critical humidity corresponding to the applied pressure and providing the transition of the system into a twophase state at the end of the pressing process.

\section{SUMMARY}

Experimental studies of the effect of particles characteristics of inorganic powders and their moisture on rheological properties of the friable material, as well as review of publications on the autohesion phenomenon in inorganic compound powders made it possible to come to the following conclusion:

- autohesion has both positive and negative influence on technological processing of friable powder materials. So, autohesion acts favorably when it is necessary to reduce the dispersivity of powders or prevent the powder mixture from delamination. At the same time, by mixing powders due to autohesion the homogeneity of the mixture may be substantially violated by the formation of aggregates;

- the magnitude of the autohesion forces is primarily determined by the particles size. On average, the autohesion manifests itself in friable materials, which consist of particles smaller than $100 \mu \mathrm{m}$; 
- in addition to the particles size the magnitude of the autohesion forces is determined by a number of factors, such as: chemical composition and structure of the particle material, particle morphology, particle size distribution, humidity, the presence of surfactants, method and conditions of forming blanks;

- with identical chemical composition and similar particle size distribution the strength of powders autohesion can considerably vary. Therefore it is not enough to analyze the particle size distribution and specific surface area in order to characterize the rheological and technological properties of corundum powders in the size range studied;

- the capillary adhesion maximum is set spontaneously at critical values of the powder humidity and the corresponding humidity values are optimal from the point of view of maximum adhesion in the dispersed system, its greatest degree of compaction, as well as the greatest strength of the annealed products.

Summarizing the conclusions, one can conclude that the study of autohesion of the friable powder materials is an urgent task for modern applied science, engineering and technology. The main objectives of the study of the autohesion phenomenon can be the prediction of the properties of powder materials and the rational planning of technological of their processing, storage and transportation.

\section{ACKNOWLEDGEMENT}

This work has been performed with financial support from the Ministry of Education and Science of the Russian Federation within the framework of the Federal Targeted Programme "Research and Development Works in the Priority Development Areas of the Science and Technology Complex of Russia for 2014-2020" under the Agreement No. 14.577.21.0221 dated September 29, 2016 on the subject of the "Technology Development for Grain Oriented Piezoceramics Intended for the Manufacture of Components of Perovskite-Like Oxide Ferroelectric Material-Based Control and Positioning Devices" (unique identifier ПНИЭРRFMEFI57716X0221), using the equipment of the Research Resource Centre of the Moscow Polytechnic University.

\section{REFERENCES:}

[1] D. A.Simon and E. I. Andrianov, Autogeziya sypuchikh materialov (Metallurgia, 1978), In Russian.
[2] Yu.P. Udalov and A.M. Germanskiy, Tekhnologiya neorganicheskikh poroshkovykh materialov i pokrytiy funktsionalnogo naznacheniya (Janus, St. Petersburg, 2001), In Russian.

[3] V. A. Arsentyev, L. A. Vaysberg and I. D. Ustinov // Obogashcheniye rud 5 (2014) 3, In Russian.

[4] V. A. Tyzykhyan // Niva Povolzhya 1 (2010) 73, In Russian.

[5] S. A. Evtukov and A. A. Simanova // Zeszyty Naukowe Politechniki Częstochowskiej. Budownictwo 21 (2015) 67.

[6] V. I. Bashkirtsev and L. A. Yuditskiy // Servis v Rossii i za rubezhom 3 (2012) 261, In Russian.

[7] A. A. Sobolev, P. A. Melnikov and A. A. Tyutyunnik // Vektor nauki Toliattinskogo gosudarstvennogo universiteta 3 (2011) 82, In Russian.

[8] V. P. Kuznetsov // Kemerovo State University Bulletin 1 (2014), 173, In Russian.

[9] A. A. Gaidai and V. I. Suhl // Ugol Ukrainy 1 (2013) 39.

[10] M. V. Sevostyanov // Research Journal of Applied Sciences 10 (2015) 684.

[11] F. Podczeck, J. M. Newton and M. B. James // Chemical and pharmaceutical bulletin 11 (1995) 1953.

[12] A.D. Zimon, Adhesion of dust and powder (Springer Science \& Business Media, 2012).

[13] Hongming Li, Impact of cohesion forces on particle mixing and segregation (PhD Thesis, University of Pittsburgh, 2006).

[14] M. Halidan // AIChE Journal 4 (2016) 1023.

[15] J. Bridgwater // Powder Technology 2 (1976) 215.

[16] N. A. Orr and E. Shotton // Chemical Engineer-London 269 (1973) 12.

[17] E. J. R. Parteli // Scientific reports 4 (2014) 6227.

[18] N. Ku // Procedia engineering 102 (2015) 72.

[19] N. Ku, Evaluation of the behavior of ceramic powders under mechanical vibration and its effect on the mechanics of auto-granulation (PhD Thesis, Rutgers University, 2015).

[20] A. Castellanos // Advances in physics 4 (2005) 263.

[21] R. Chirone // Powder Technology 323 (2018) 1.

[22] B. L. Krasny, V. P. Tarasovsky, A. B. Krasny and A. L. Kuteynikova // Novyye ogneupory 9 (2007) 45. 
[23] M.A. Smirnov, Sukhiye obshchestroitelnyye smesi s uluchshennymi ekspluatatsionnymi svoystvami (Ph.D. Thesis, Tver State University, 2006).

[24] A. I. Zimin, A.L. Sumenkov and V.V. Aseev // Izvestiya TuIGU. Tekhnicheskiye nauki 2 (2014) 74.

[25] V.P. Tarasovsky // Novyye ogneupory 3 (2016) 76, In Russian

[26] B.L. Krasnyy, V.P. Tarasovskiy, A.B. Krasnyy and A.M. Uss // Novyye ogneupory 12 (2009) 20.

[27] V.P. Tarasovskiy, A.D. Shlyapin, A.Yu. Omarov, A. A. Vasin and M.N. Kormilitsin // Novyye ogneupory 9 (2018) 35.

[28] T. Pöschel and T. Schwager, Computational Granular Dynamics (Springer, Heidelberg, 2005).

[29] M. Götzinger and W. Peukert // Powder Technol. 130 (2003) 102.

[30] M. Götzinger and W. Peukert // Langmuir 20 (2004) 5298.

[31] Q. Li, V. Rudolph and W. Peukert // Powder Technol. 161 (2006) 248.

[32] H.D. Ackler, R.H. French and Y.M. Chiang // Journal of Colloid and Interface Science 2 (1996) 460.

[33] S. Matsusaka, H. Maruyama, T. Matsuyama and M. Ghadiri // Chem. Eng. Sci. 22 (2010) 5781.

[34] E. J. R. Parteli and T. Pöschel // Powder Technology 288 (2016) 96.

[35] J. N. Israelachvili, Intermolecular and surface forces (Academic press, 2011).

[36] P. A. Rebinder, Surface phenomena in disperse systems. Physico-chemical mechanics. Selected works (Nauka, Moscow, 1979).

[37] Introduction to particle technology, ed. by M. Rhode (John Wiley and Sons, New York, 1998).

[38] Processing of Particulate Solids, ed. by J. P. K. Seville, U. Tuzun and R. Clift (Blackie Academic and Professional, London, 1997).
[39] Yu.V. Naydich and I.A. Lavrinenko // Poroshkovaya metallurgiya 10 (1965) 61, In Russian.

[40] Kazuyuki Hotta, Kazuo Takeda and Koichi linoya // Powder Technol. 4 (1974) 5.

[41] B. V. Deryagin // Zhurnal fizicheskoy khimii 2 (1940) 137, In Russian.

[42] Yu. Naiditsch, I. A. Lavrinenko and V. J. Petrishchev // Poroshkovaya metallurgiya 2 (1965) 23, In Russian.

[43] G. I. Pokrovskiy, Research on the physics of soils (ONTI, Moscow-Leningrad, 1936).

[44] V. I. Korotich, Teoreticheskiye osnovy okomkovaniya zhelezorudnykh materialov (Metallurgy, Moscow, 1966).

[45] V. V. Belov, Perspektivnyye stroitelnyye materialy i tekhnologii (TVSTU, Tver, 2017).

[46] V. V. Timashev and L. M. Sulimenko, Albac agglomeration of powdered silicate ma Aglomeratsiya poroshkoobraznykh silikatnykh materialov (Stroyizdat, Moscow, 1978).

[47] M. C. Coelho // Powder Technol. 2 (1978) 201.

[48] L. W. Petersen, P. Moldrup, O. H. Jacobsen and D. E. Rolston // Soil Science 161 (1996) 9.

[49] T. G. Plachenov and S. D. Colasanti, Porometry (Chemistry, Leningrad, 1988).

[50] ISO 903-76 Alumina, Method for determination of bulk density.

[51] ISO 3953-85 Metal Powders. Density determination after tapped.

[52] L.L.Bernay and V.V. Belov // Fizikokhimicheskaya mekhanika: Zhurn. Bolgarskoy akad. Nauk 10 (1982) 12.

[53] V.V. Belov, T.B. Novichenkova and I.V. Obrazcov // Nanotekhnologii v stroitelstve: nauchnyy Internet-zhurnal 4 (2010) 23.

[54] V.V. Belov // Stroitelnyye materialy 9 (2009) 42, In Russian.

[55] A.A. Suslov, E.I. Shmit'ko and A.T. Vazhinsky // Izvestiya vuzov. Stroitelstvo 1112 (1998) 63, In Russian. 